\title{
Research Paper \\ Identification and Analysis of the Effective Factors of Carpet Weaving Industry Downturn in Rural Areas Using Q-Methodology (Case Study: Turkmen Carpet of Gonbad-e Kavus County)
}

\author{
*Amin Mohammadi Ostadkelayeh ${ }^{1}$, Naser Bayat ${ }^{2}$ \\ 1. Assistant Professor, Department of Watershed Management, Faculty of Agriculture and National Resources, Gonbad Kavous University, Gonbad Kavous, Iran \\ 2. Assistant Professor, Department of Geography, Faculty of Command and General Staff, Amin Police University, Tehran, Iran.
}

Cftation: Mohammadi Ostadkelayeh, A., \& Bayat, N. (2016). Identification and Analysis of the Effective Factors of Carpet Weaving Industry Downturn in Rural Areas Using Q-Methodology (Case Study: Turkmen Carpet of Gonbad-e Kavus County). Journal of Rural Research, 7(2), $392-405$.

Received: 19 Feb. 2016 Accepted: 4 May 2016

Key words: Q-methodology, Downturn, Rural economy, Gonbad-e Qavous township, Handmade Turkmen carpet

\section{A B S T R A C T}

This study tries to analyze the reasons for the downturn of the carpet weaving industry in the Golestan Province and also takes advantage of experts' opinions and viewpoints. The $Q$ methodology was used to achieve a comprehensive understanding of the causes of the downturn. A total of 26 experts of the Turkmen hand-woven carpet were selected for conducting "Q-sort" data collection procedure. The factor analysis was conducted through a heuristic method using correlation matrix in order to identify the participant's mental paradigms (viewpoints). Finally, six factors or viewpoints, with the total variance of 86.7, were identified. A total of 16 statements were offered in this regard including the following statements: 1) Lack of innovation and creativity and marketing problems; 2) Technical and technological backwardness and low economic proficiency; 3) Expensive cost of raw materials, lack of innovation; 4) The changed lifestyle and understanding carpet weaving as a hard work; 5) The weak planning system and institutional inefficiency; and 6) Lack of motivation, changed livelihood, and low economic proficiency. The results indicate that the statement 3 has the highest score (with the factor score of 2.05) among the various statements. This statement is followed by youth, especially young rural girls, unwillingness to work in carpet weaving field and learning its skills (score: 1.93) and lack of innovation and creativity in designs, colors, motifs and quality of the raw materials to improve the quality of carpets (score: 1.93).

\section{Extended Abstract}

\section{Introduction}

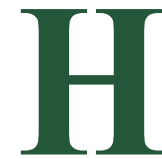

and-woven carpets are one of the most important and original handicrafts of Iran. The industry plays a key role in terms of job generation, especially in the rural areas, and non-petroleum exports; it also constitutes a considerable part of the Iran's GDP. However, the industry has faced considerable challenges during the recent years. The Turkmen hand-woven carpet, despite its ancient background and effective role in both economy and livelihood of the region's people, has shown a decreasing trend in terms of production and supply. Using an etiological approach, this study tries to analyze the reasons of downturn of the carpet weaving industry in the Golestan Province and also takes the advantage of experts' opinions and viewpoints. Accordingly, the main ques- 
tion of the study is: what are the most important causes of the downturn of Turkmen carpet weaving industry in the Golestan Province?

\section{Methodology}

Traditionally, producing hand-woven carpets has been popular among residents of this region, especially among Turkmen people. There are many women in this area who are active, either part-time or full-time, in this industry. According to the latest administrative divisions, Gobnbad-e Kavous County, with a population more than 325,789, has 2 districts, 6 rural districts and 167 residential villages and 10 empty villages (Statistical Center of Iran, 2011). According to the Industry, Mine and Trade Organization of Golestan Province, about 70,000 people in this province are known as traditional carpet weavers who have learned this craft from their precedent generations; of them, 31000 people have special ID card for carpet weaving. Most carpet weaving units of the province are concentrated in Gonbad, Bandar-e Turkmen, Aq-Qala and Kalaleh counties; Gonbad accounts for 30 percent, the highest percent, of the handwoven products of the province.

In this study, the Q methodology was used to achieve a comprehensive understanding of the causes of the downturn of carpet weaving industry in the mentioned region through reviewing the results of studies on the hand-woven carpet economy in Iran and also by analyzing the current discourse atmosphere. Then, the experts' contributions were used to identify and classify various viewpoints in this area that helped us to take a step beyond offering only some analyses. In the next stage, using the purposeful sampling method, a total of 26 experts of the Turkmen hand-woven carpet were selected for conducting "Q sort" data collection procedure. When the sorting stage was finished, a data matrix was formed in the SPSS software for analyzing data. As the Q methodology's logic specifies, the Q Factor Analysis method, which is the main method for analyzing the Q data matrix, was used.

\section{Results}

Using the rotated factor matrix and measuring factor loadings above 0.5 , a total of six factors or viewpoints, with the total variance of 86.7 , were extracted. A total of 16 statements were offered in this regard, including statements such as: 1) Lack of innovation and creativity and marketing problems; 2) Technical and technological backwardness and low economic proficiency; 3) Expen- sive cost of raw materials and lack of innovation; 4) The changed lifestyle and understanding carpet weaving as a hard work; 5) Weak planning system and institutional inefficiency; and 6) Lack of motivation, changed livelihood, and low economic proficiency.

\section{Discussion}

With regard to the results of this study and as the number and form of groupings shown, the range of ideas and viewpoints of the participants on causes of the downturn in the hand-woven carpet industry in the rural areas of the Golestan Province have both similarities and differences. The results indicate that the statement (3), expensive cost of raw materials, with the factor score of 2.05 has the highest score among the various statements.

\section{Conclusion}

This statement is followed by youth, especially young rural girls, unwillingness to work in carpet weaving field and learn its skills (score: 1.93) and lack of innovation and creativity in designs, colors, motifs and quality of the raw materials to improve the quality of carpets (score: 1.93). 


\title{
شناخت و تحليل عوامل مؤثر بر ركود صنعت قالى بافى در نواحى روستايى با استفاده از روش كيو (مورد مطالعه: شهرستان تُنبد مؤروس)
}

\author{
"امين محمدى استادكلايه'، ناصر بيات' \\ ا. استاديار، كروه مرتع و آبخيزداري، دانشكده كشاوزى و منابع طبيعى، دانشكاه كَنبدكاووس، كنبدكاووس، ايران.

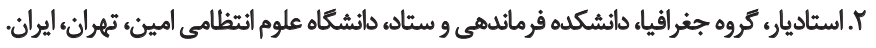

\begin{abstract}
حكبد

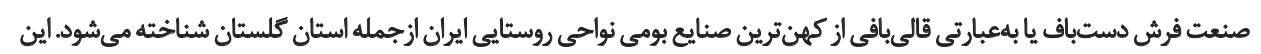

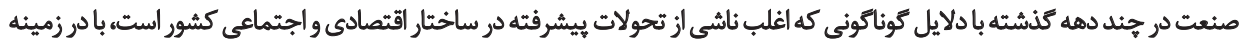

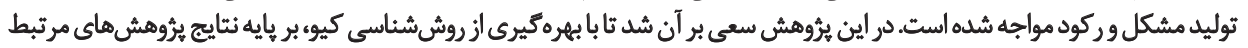

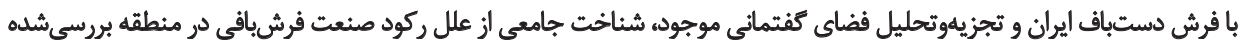

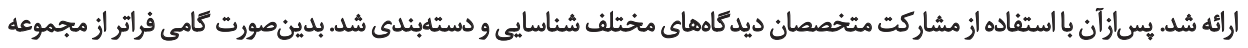

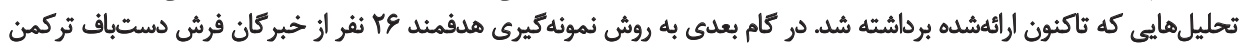

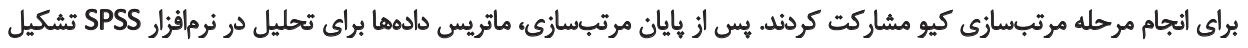

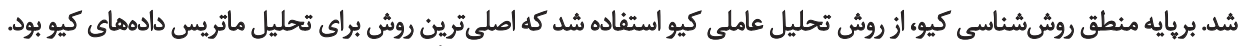

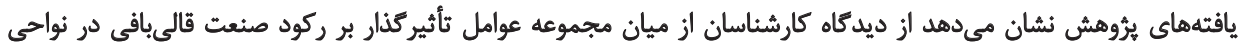

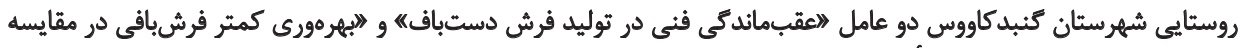

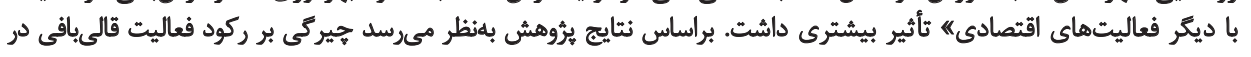

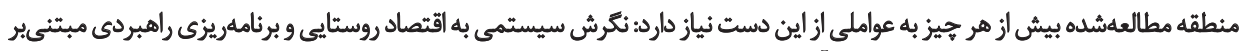

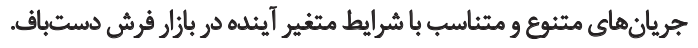

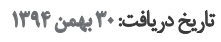

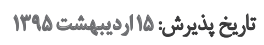

Sham Abadi \& فرشباف كشور در نواحى روستايى سكونت دارند

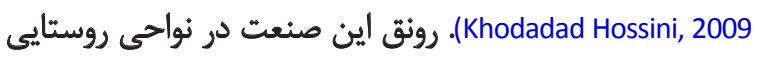

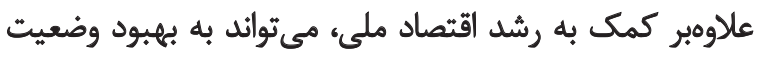

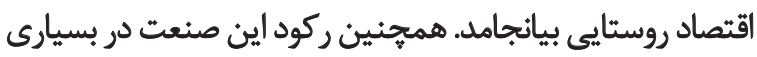

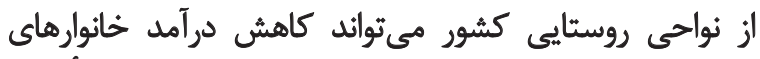

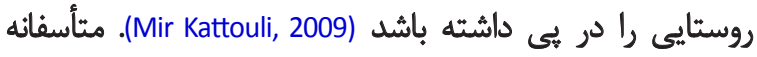

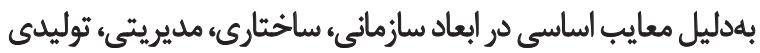

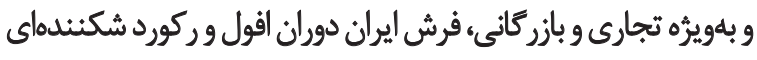

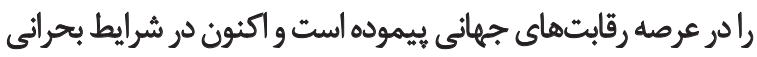

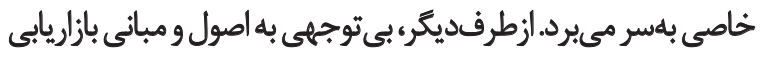

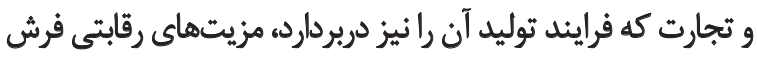

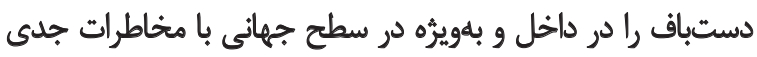
مواجه كرده است. كفتنى است تجربه موفق ديخر كشورها از توجيه

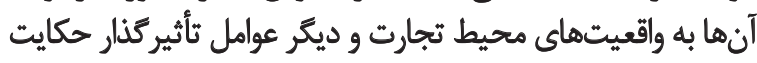

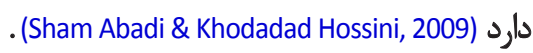

doto.)

قالى بافى يكى از كهن ترين فعاليتهاي اقتصادى در ايران بهشمار

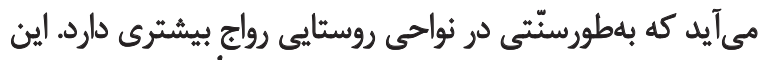

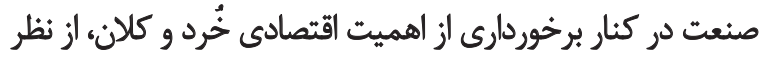

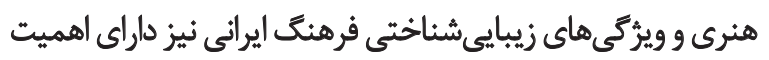

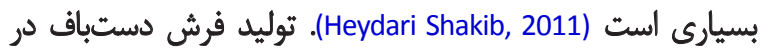

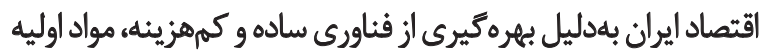

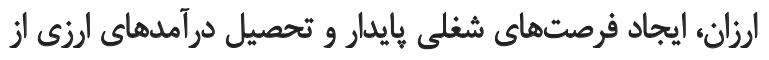

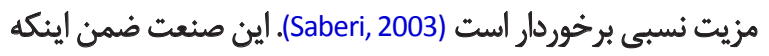

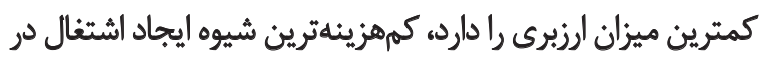

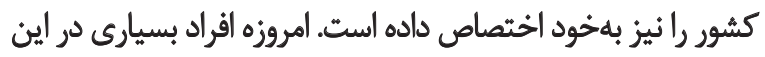

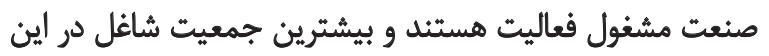

صنعت را زنان تشكيل مي مهند (Shajari \& Ghavami, 2003). براساس آمارهاى مختلف بيش از ه ه درصد جمعيث 
بهينهارى تصميمكيرىها و سرانجام امكانيذيرى و واقع كرايى طرحها كمك كرد (Eynali \& Taher Khani, 2006).

ازجمله عوامل داخلى ديكر سياستهاى تجارى و ارزى متفاوت

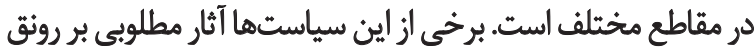

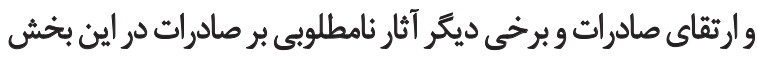

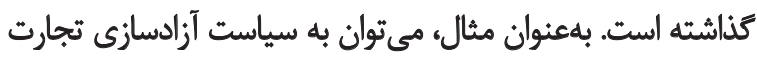

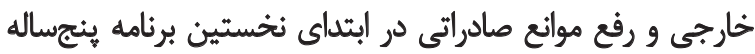

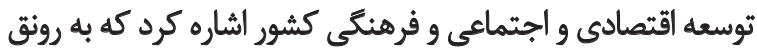

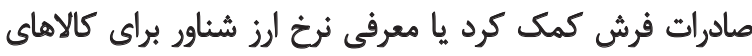

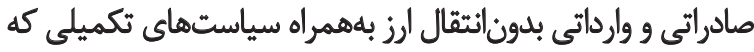
در امر توسعه صادرات نقش مؤثر داشته است.

دراينميان از عوامل خارجى مؤثر بر كاهش صادرات در سال هاى

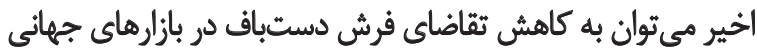

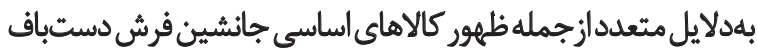

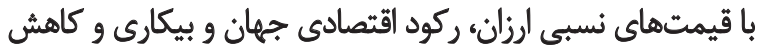

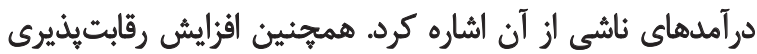

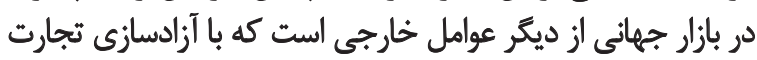

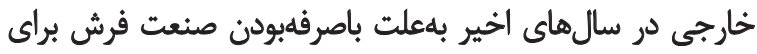

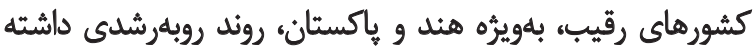

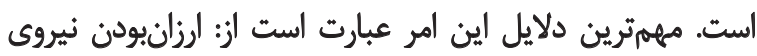

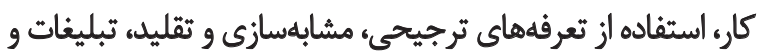

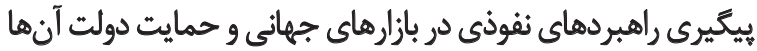
از قالىبافان (Shajari \& Ghavami, 2003).

برخى مسائل از قبيل رشد تعداد مصرفكنئده در مقايسه با بإيا

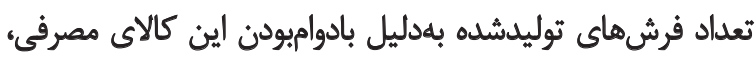

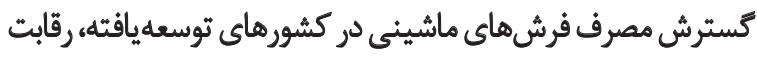

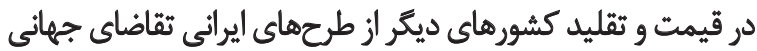

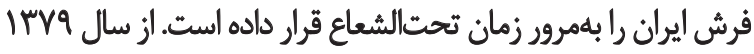

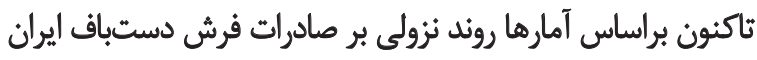

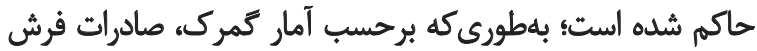

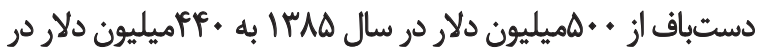

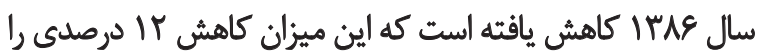
نشان مي دهد (Azouji, 2013).

\section{ي بيشينه تحقيق}

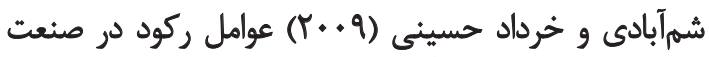

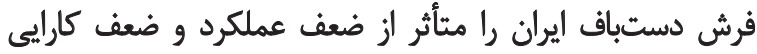

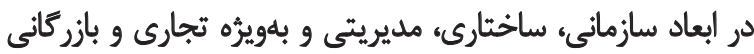

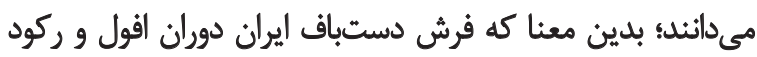

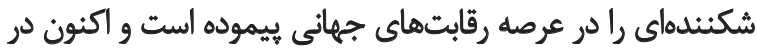

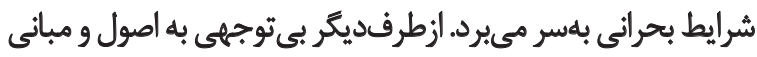

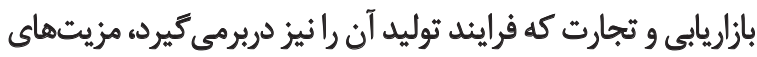

توليد فرش دستباف در استان كلستان از ديرباز ميان ساكنان

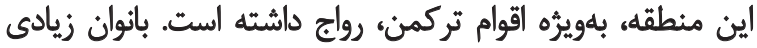

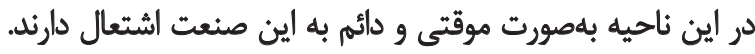

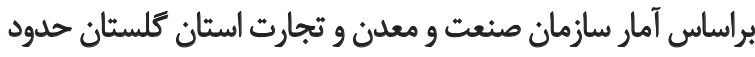

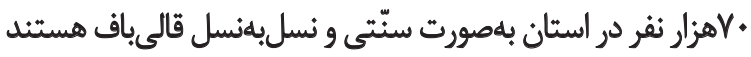

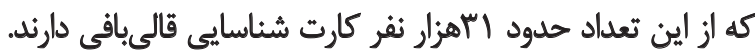

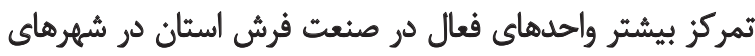

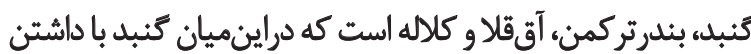

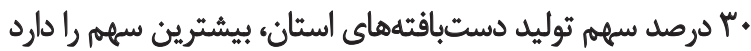

(Adeli, 2013)

فرش تركمن طى سالهاى اخير، بلويرّه در ابعاد كيفى، دجار

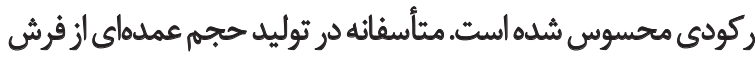

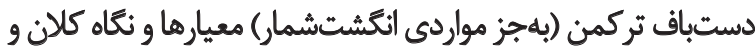

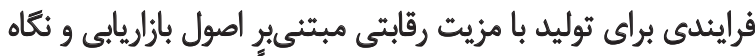

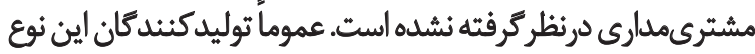

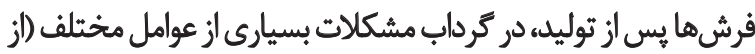

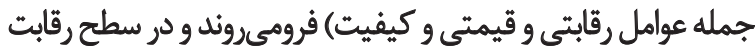

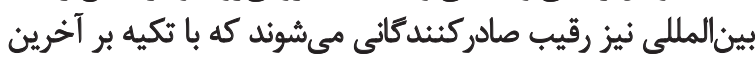

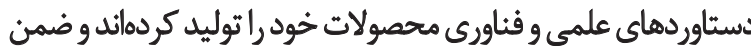

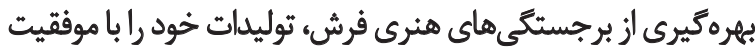
به فروش مىرسائند (Esfandiari, Tajpouri, \& Pakzad, 2010).

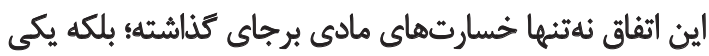

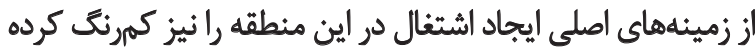

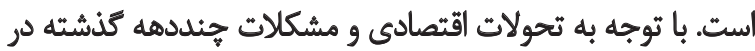

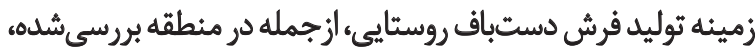

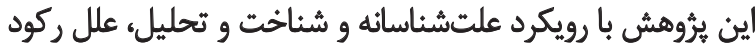

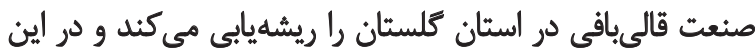

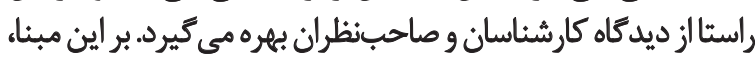

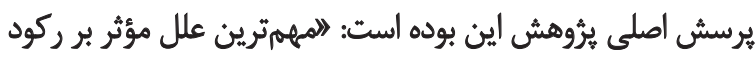

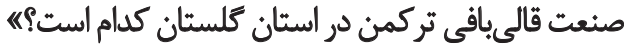

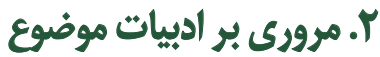
اهميت اقتصادى فرش دستباف و دلايل ركود أن صنعت فرش يكى از معدود صنايعى است كه بهواسطه قدمت

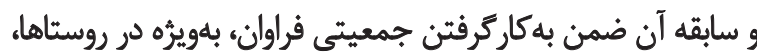

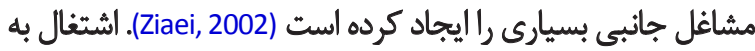

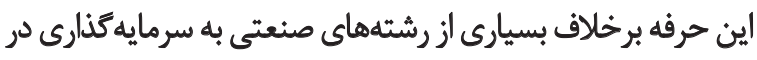

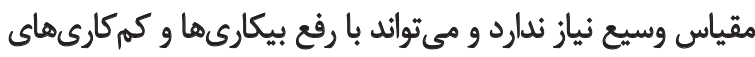

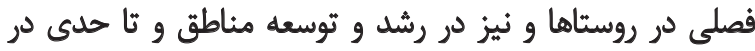

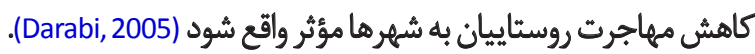

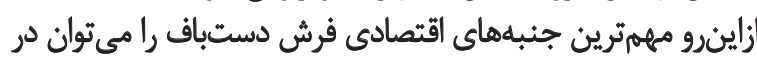

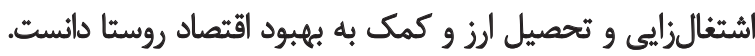

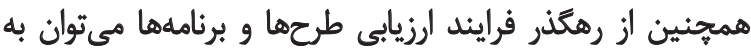




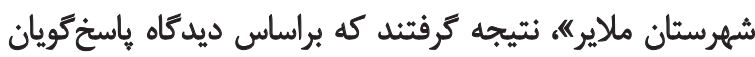

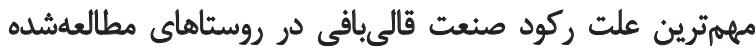

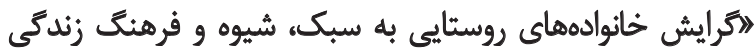

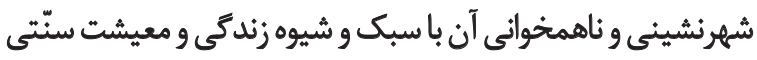

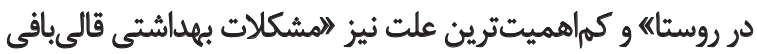
به سبك سنّتى در خانها است.

منطقdمالعهشيده

جمعيث شهرستان كنبدكاووس افزونبر

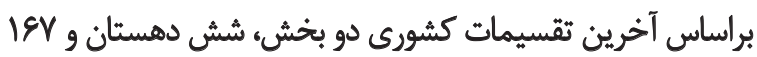

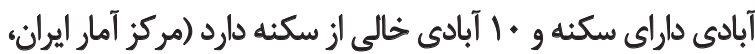

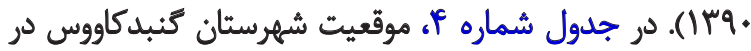

كشور و استان كلستان نشان داده شده است (تصوير شماره ()).

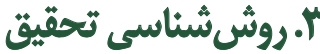

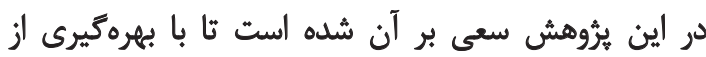

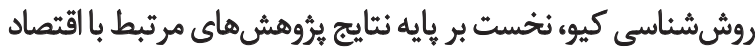

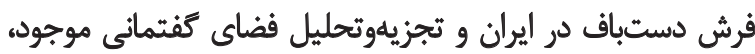

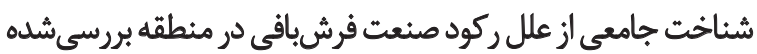

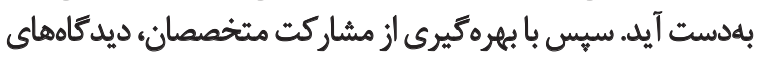

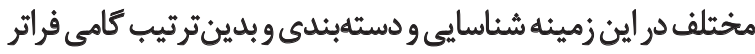
از مجموعه تحليلهاى ارائهشده برداشته شود. از اين رهئندر انتظار

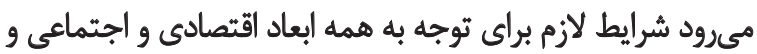

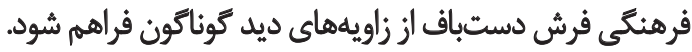

$$
\text { مطالعه و تمردآورى فضاى تَّثنمان }
$$

در اين تئوهش تمام مقالههاى علمى، تزارش هاى خبرى، منابع

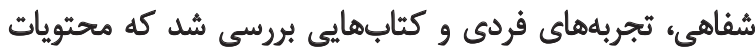

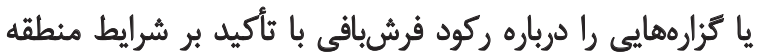

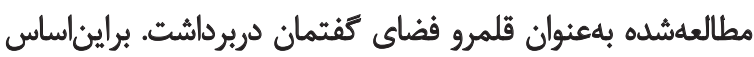

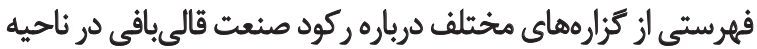

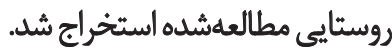

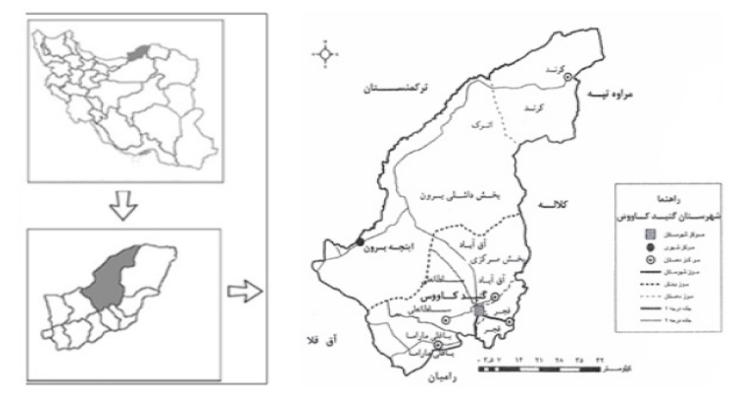

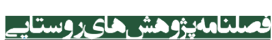

تصوير ا. موقعيت شهرستان كنبدكاووس در كشور و استان كلستان.
رقابتى فرش دستباف را در داخل و بهويرُه در سطح جهانى، با دوريا

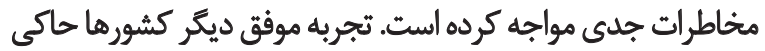
از توجه آنها به واقعيثهاى محيط تجارت وديث وديكر عوامل تأثيركذار أست (Sham Abadi \& Khodadad Hossini, 2009).

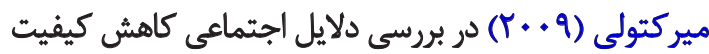

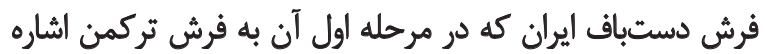

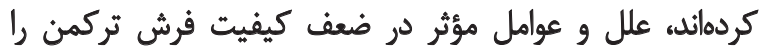

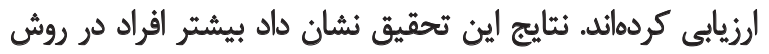

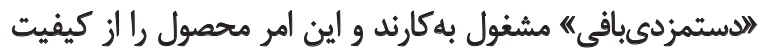

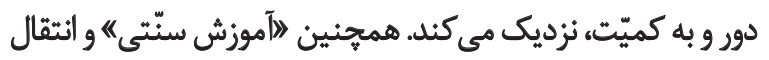

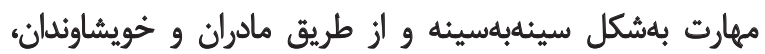

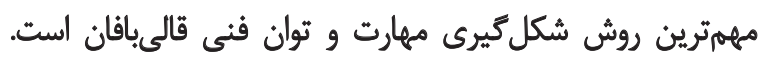

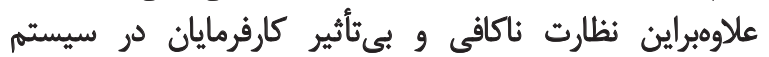

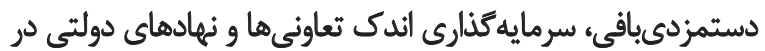

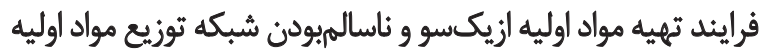

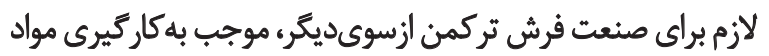
نامرغوب توسط بافندكان و افت كيفيت فرش شرئ شده است.

علىيورى (1999) در تحقيقى درباره دار و ابزار قالى بافى دئ،

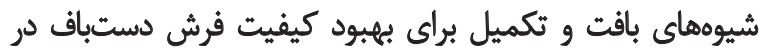

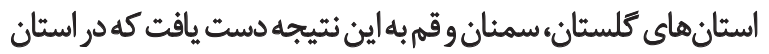

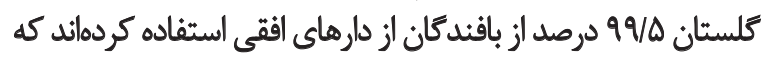

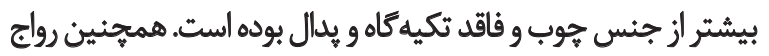

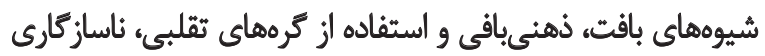

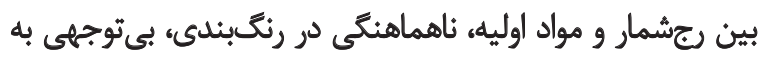

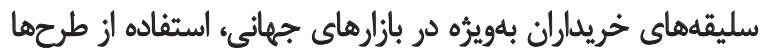

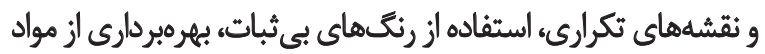

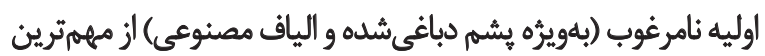

$$
\text { دلايل كاهش كيفيت فرش دستباف تركمن است باغئ }
$$

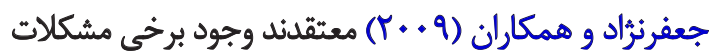

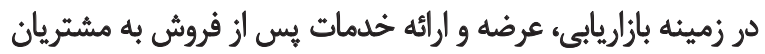

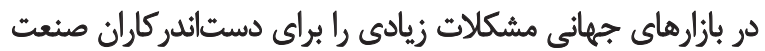

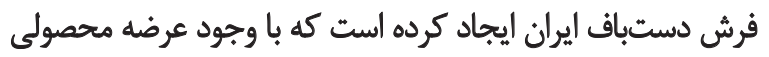

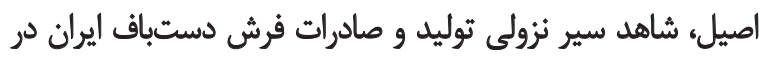

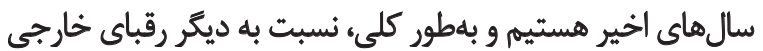

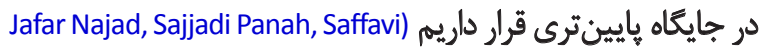

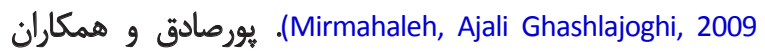

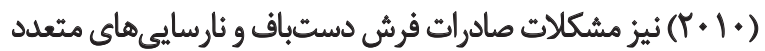

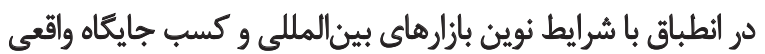
را عامل ركود مي دانند (Poursadegh, Bohlooli, Hajikhani, 2010).

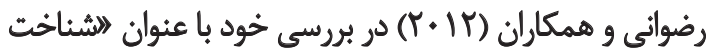

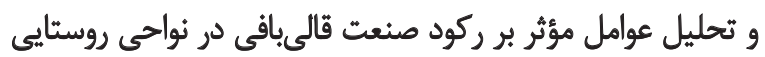




\begin{tabular}{|c|c|c|c|c|c|c|}
\hline$r$ & $\&$ & $\Delta$ & $r$ & $r$ & $r$ & 1 \\
\hline & & & & & & \\
\hline & & & & & & \\
\hline & & & & & & \\
\hline & & & & & & \\
\hline & & & & &
\end{tabular}

كمئمة

تصوير r. نمودار كيو (منبع: نكارندكان).

شكل مانند طيف ليكرت، جند طيف را دربرمى ئيرد؛ بهطورى كه

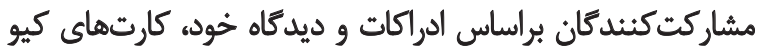

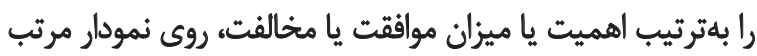

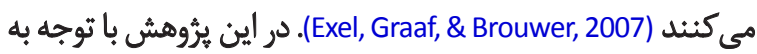

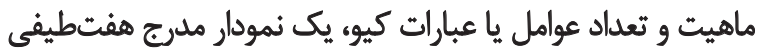

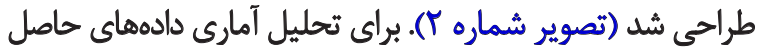

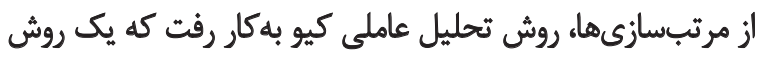

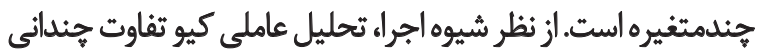

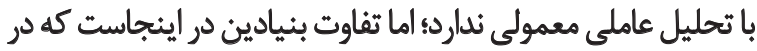

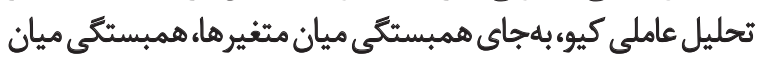

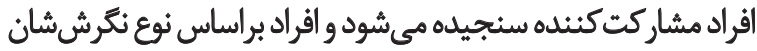

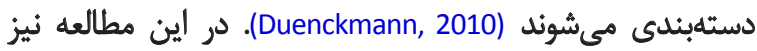

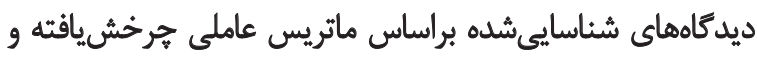

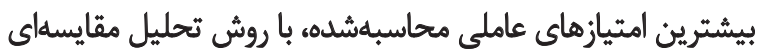
تفسير شد.

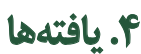

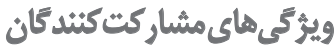

در تحقيق حاضر به روش نمونه كيرى هدفمند، تعداد عץ نفر

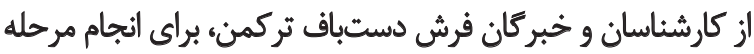

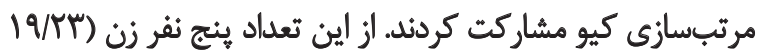

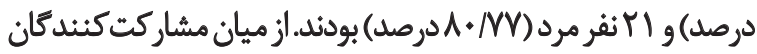

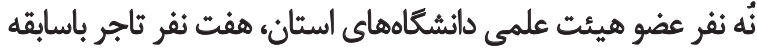

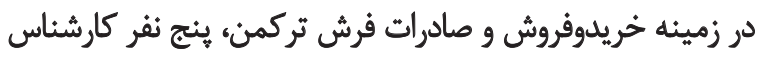

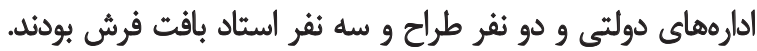

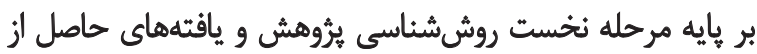

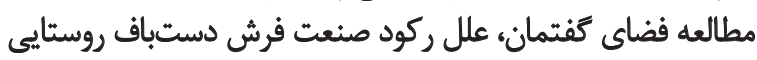

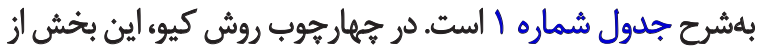

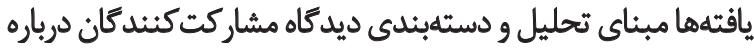
علل ركود صنعت فرش تركمن شهرستان قرار كرفينت

تحليل دادهها

يس از يايان مرتبسازى براى تحليل دادهها، ماتريس دادهها

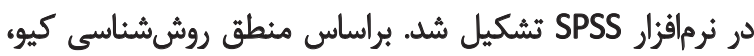

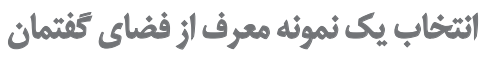

در روش كيو، يك نمونه كيويى مطمئن بايد همه ابعاد فضاى كفتمان را يوشش دهد (Ellingsen, Størksen, \& Stephens, 2010).

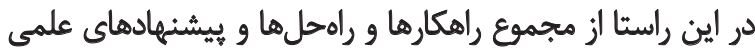

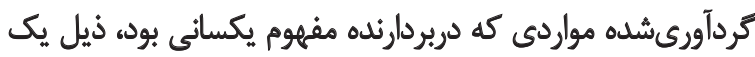

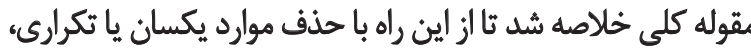

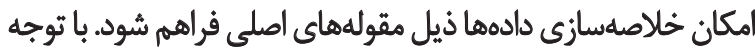

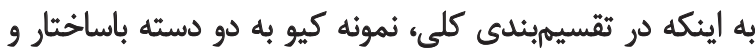

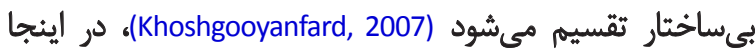

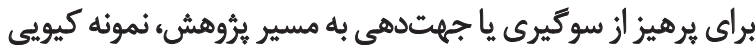

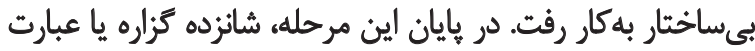

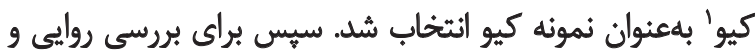

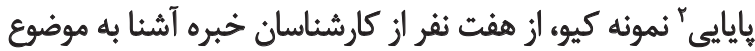

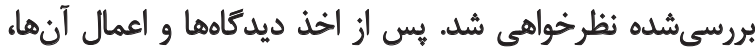

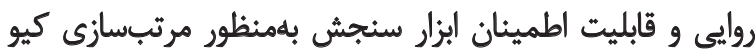

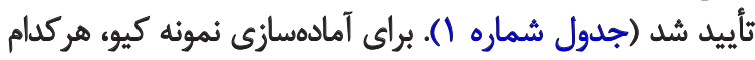

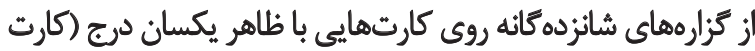

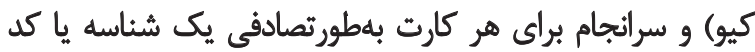
تعيين شد.

انتخابمشاركت كندانَان

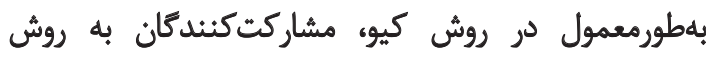

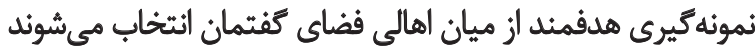

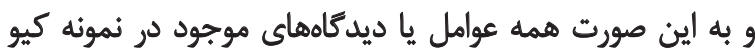

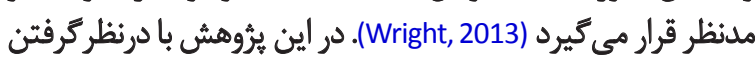

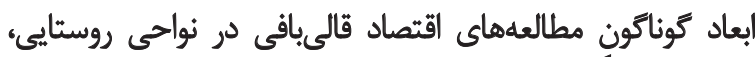

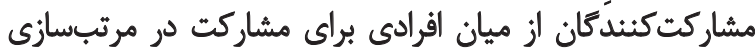

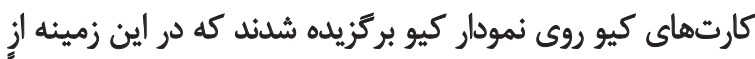

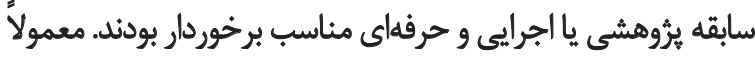

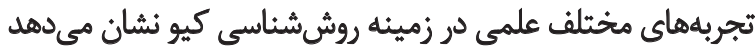

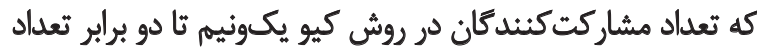

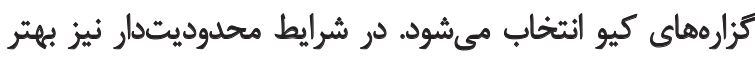

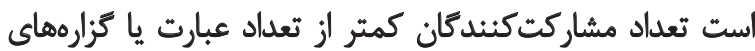

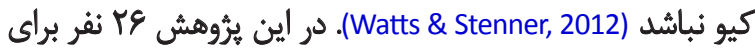

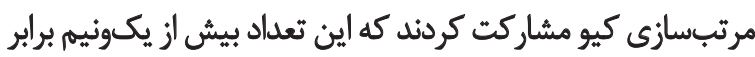

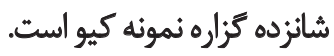

$$
\text { طراحي نمودار كيو، مرثبسازى و تحليل عاملي كيو }
$$

در بيشتر يروهشهايي كه با روش كيو انجام مىشود، نمودار

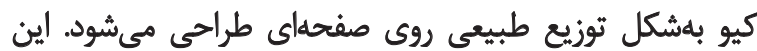

1. Q statement

2. Reliability 
براى شناسايى القوهاى ذهنى مشاركت كنيدكان تحليل

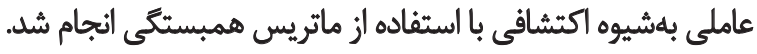

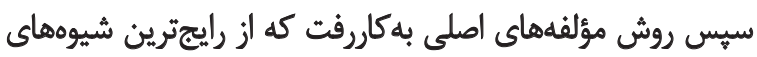

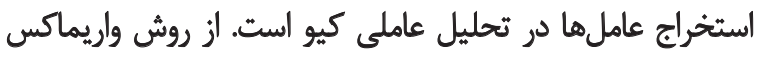

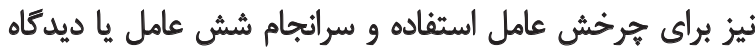

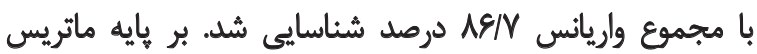

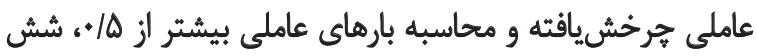

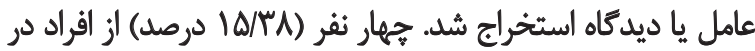

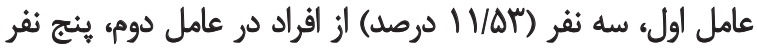

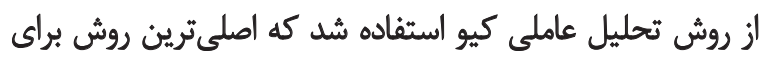

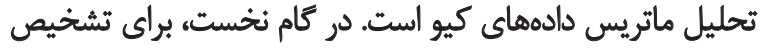

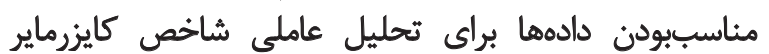
"(KMO)

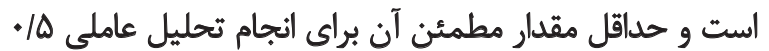

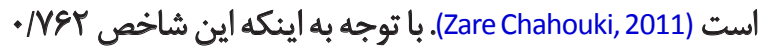
بهدست آمد، دادهها مطمئن تشخيص داده شد (جدول شماره ؟).

3. Kaiser-Mayer-Olkin

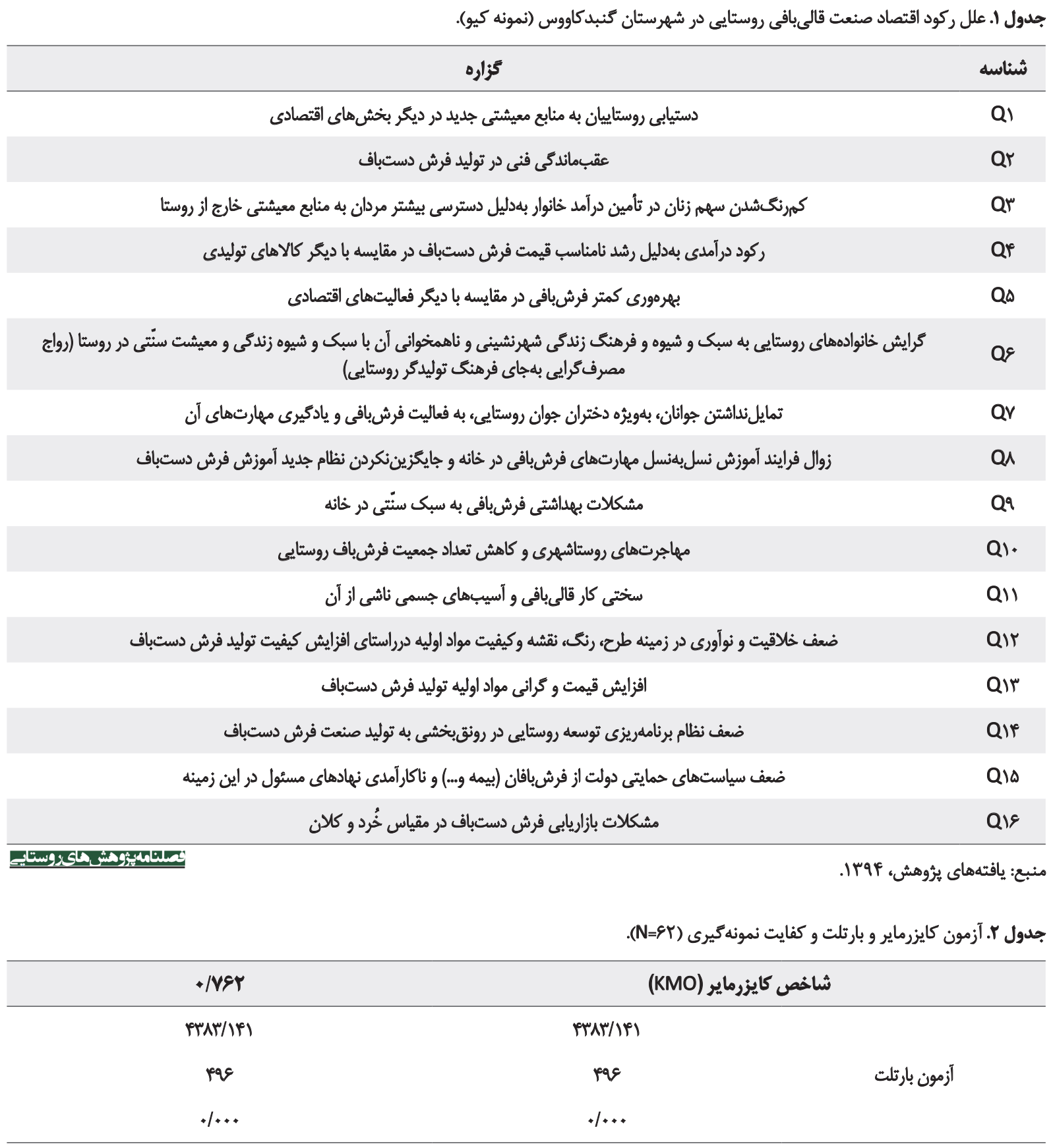


جدول ץ. يافتههاي تحليل عاملى كيو.

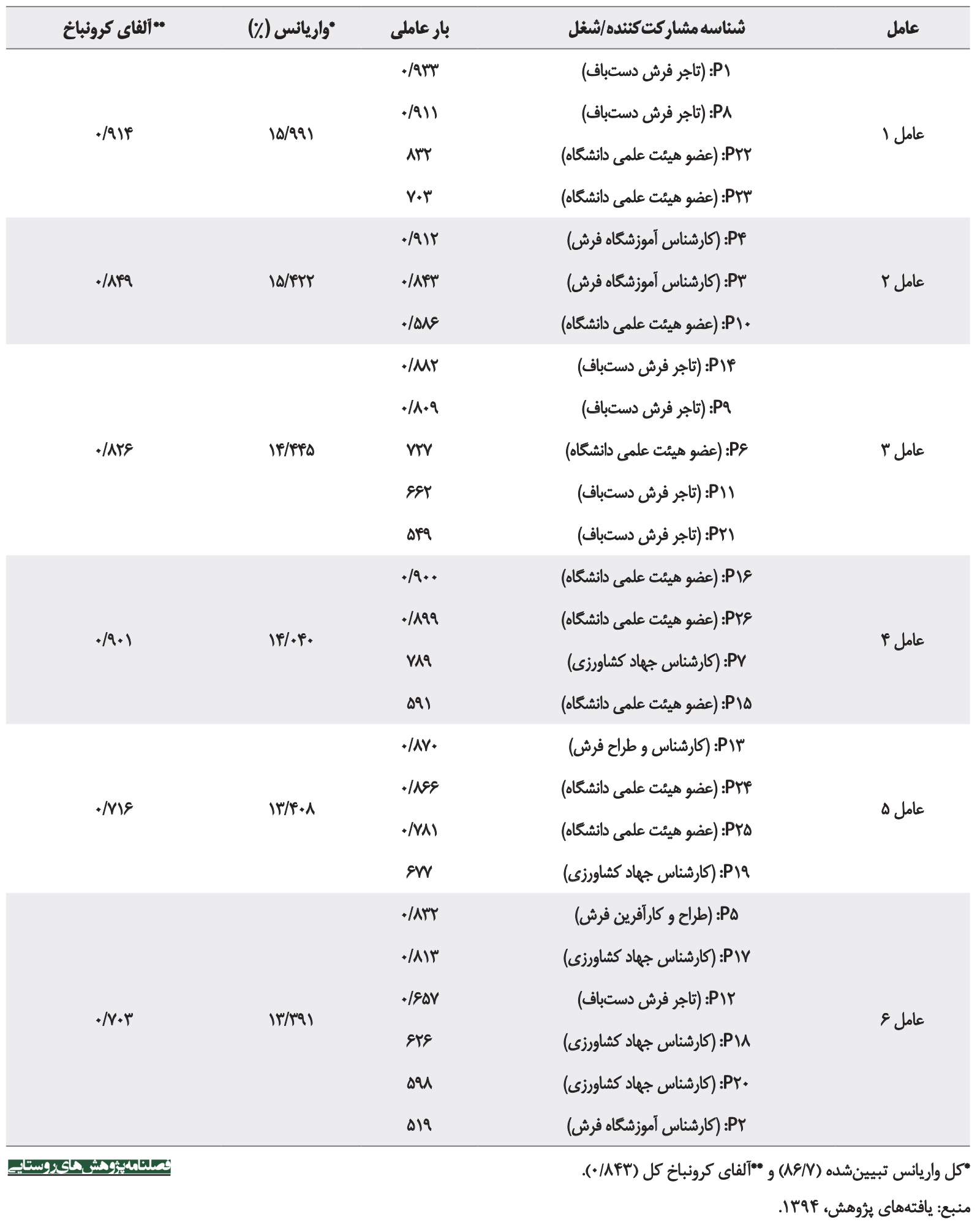

ميزان هايايى هريك از عاملها محاسبه و سرانجام در همه موارد

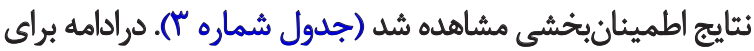

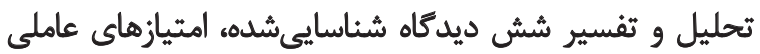

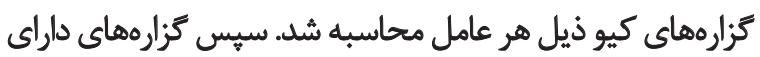

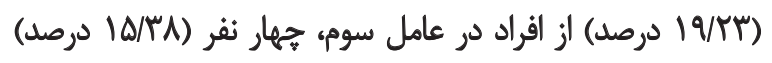

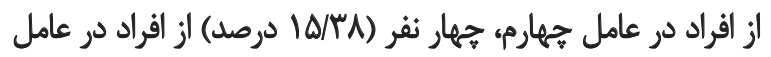

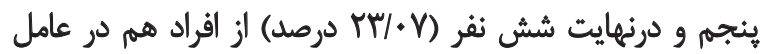

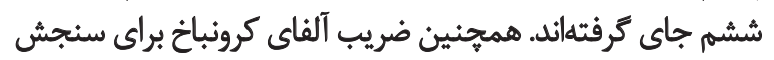


جدول F. امتيازهاي عاملى كزار ههاي ركود اقتصاد قالى بافى در هريك از عامل ها (كروه مشاركتكنيده).

\begin{tabular}{|c|c|c|c|c|c|c|}
\hline كروه & كرو ه & Fروه & كروه r & كروه r & كروه | & شُناسه كّزاره \\
\hline VerQR & ./99meт & WTH & .1.11994 & $-\cdot M T I \Delta S$ & - /arive & Q) \\
\hline +/VIreV & 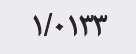 & +|EIAYA &.$/ 4 T \cdot 9 f$ & I/FAVTE & ./TAIEA & Qr \\
\hline$-1 / 1 M q$ & $-+|\Delta \lambda| \lambda \mid$ &.$M \cdot 8 V$ & $-1 / \Delta+4 q 1$ &.$/ 4498 \lambda$ & $+1+r++q$ & Qr \\
\hline - & - MAPVI & - Mrava & I. & 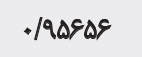 & $-1 / f \cdot V \neq \Delta$ & Qr \\
\hline$V / r+r \cdot V$ & - /IMTAP & - /prtar & - -apeq & |r|m & - /NPaAr & QD \\
\hline . /19PAA & -./.vary & V/e.prr & $. / 8+1 f F$ & -I/refe & - MITAF & $Q 8$ \\
\hline V/uniq &.$- /$ retar & $-\cdot$ /EIfT & $-* / 1 \cdot$ rar & $-\cdot|r \Delta|+r$ & $-1 /$ reser & QV \\
\hline$-* / W \cdot \Delta r$ & - /PVIVA & $.10 .1 \times 9$ & -. /ATMIV & ./MMIr & - IEAleE & Q1 \\
\hline$. / T+R T R$ & $-1 / \Delta 911$ & ./mtrar & $-1 /$ TIQP & .1 .9 .1 &.$- /$ PVATY & Qq \\
\hline -./rפונו & -1/MTT & $-1 /$ pipin & $1 / \cdots+1$ & $-\cdot$ TrATr &.$- / 9 \Delta .99$ & Q). \\
\hline -. / & $1 / .24$ & IrFoir & $-. / r+199$ & - Ieverar & - I/Eegr & Q11 \\
\hline & -./QVTr & - - /rTar & V/ब1Q.r & ./ITrIr & V/ameq1 & QIT \\
\hline$-* / 110 \Delta \cdot 8$ & $-.1 .94 r^{2}$ & - /APYA & $r / \cdot \Delta V \cdot T$ &.$/ 29|1|$ & . IAETTY & QIr \\
\hline$-\cdot M I I M$ & V/EVAYA & -I/FAMTA & &.$/ 9101 f$ & . MMr & Qif \\
\hline -1/Mrger & $|/| \Delta \Delta P \mid$ & -I/VEgar & $-/ T F \Delta \Delta$ & $-1 / 8 \cdot T \Delta Q$ & $-.1 \cdot+1891$ & Q10 \\
\hline . & 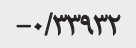 & - /AMIEN & - I/KATM & $-1 / 8 q r+1$ & WTIMIT & Q19 \\
\hline
\end{tabular}

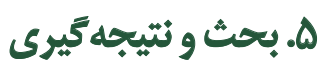

صنعت فرش دستباف از ديرباز نقش مهمى در حيات اقتصادى

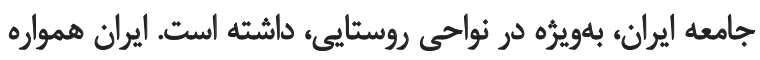

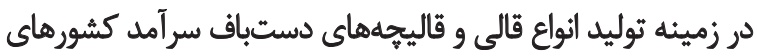

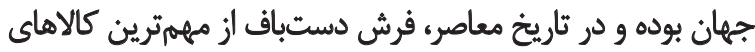

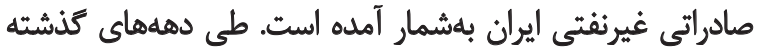

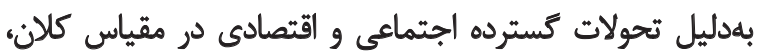

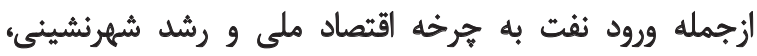

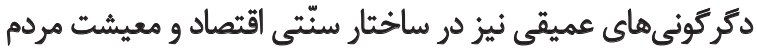

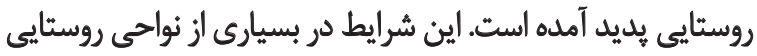

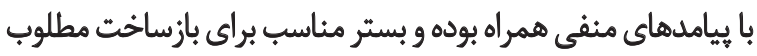

امتياز عاملى بيشتر از عدد V/ • مبناي تفسير و مقايسه ديدكاهها

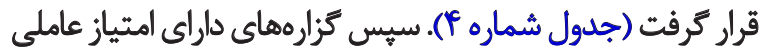

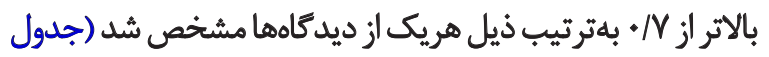

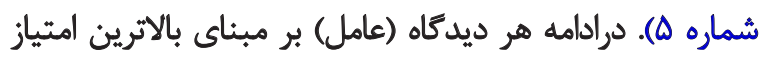

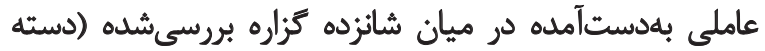

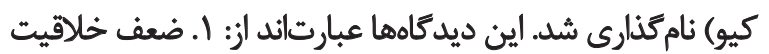

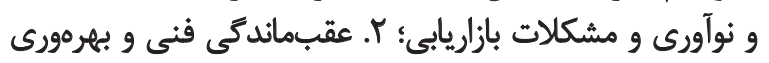

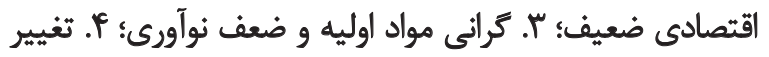

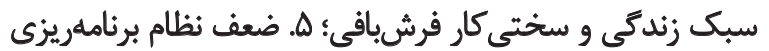

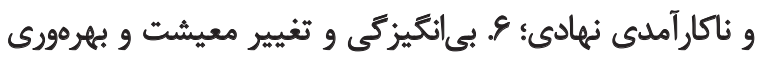
اقتصادى ضعيف.

جدول ه. ترتيب كزارهاى داراى بيشترين امتيازهاى عاملى در هر ديدكاه (عامل).

\begin{tabular}{|c|c|c|}
\hline 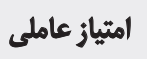 & تمزاره & ديدكاه \\
\hline Var & ضعف خلاقيت و نوآورى در طرح، رنك، نقشه وكيفيت مواد اوليه درراستاى افزايش كيفيت توليد (QIY) & \\
\hline V/rT & مشكلات بازاريايى فرش دستباف در مقياس خرد و كلان (Q19) & 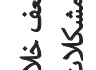 \\
\hline . $/$ Ar & بهرهورى كمتر فرشبافى در مقايسه با ديكر فعاليتهايى اقتصادى (QD) & $\frac{13}{3}$ \\
\hline$\cdot M$ & 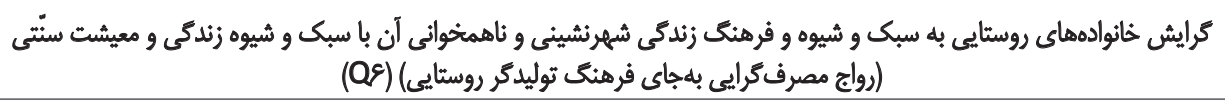 & 戀 \\
\hline
\end{tabular}




\begin{tabular}{|c|c|c|}
\hline 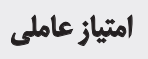 & كزّاره & ديدكّه \\
\hline $1 / F \Delta$ & عقباماندى فنى در توليد فرش دستباق (QY) & \\
\hline $1 / T^{*}$ & بهرهورى كمثر فُرشبافي در همقايسه با ديكر فعاليتهاي اقتصادي (QD) & \\
\hline.$/ 99$ & كمرنكشدن سهم زنان در تأمين درآمد خانوار بهدليل دسترسى بيشتر مردان به منابع معيشتى خارج از روستا (باته) & \\
\hline.$/ Q$ & رود درآمدى بهدليل رشد اندى قيمت فرش دستباف در مقايسه با ديكر كالاهاى توليدى (QF) & \\
\hline.$/ 91$ & ضعف نظام برنامهريزى توسعه روستايى در روثقبخشى بله توليد صنعت فرش دستباف (QIf) & \\
\hline$r / \circ \Delta$ & افزايش قيمت و كرائى مواد اوليه توليد فرش دستباف (QIT) & $\frac{2}{2}$ \\
\hline $1 / \Delta \Lambda$ & ضعف خلاقيت و نوآورى در طرح، رنك، نقشه وكيفيت مواد اوليه درراستاى افزايش كيفيت توليد (QIT) & \\
\hline $1 *$ & مهاجرتهاى روستاشهرى و كاهش تعداد جمعيت فرشباف روستايى (Q1.) & gू \\
\hline $1 / 8$. & 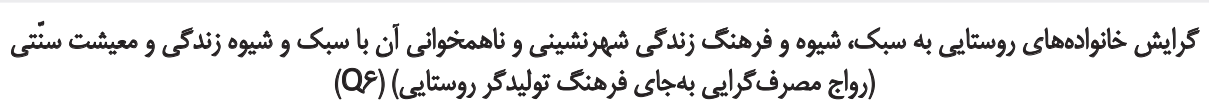 & 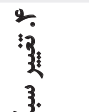 \\
\hline V/ev & ستختى كار قالىبافى و آسيبهاى جسمى ناشى از آن (Q11) & \\
\hline.$/ A f$ & افزايش قيمت و كرانى مواد اوليه توليد فرش دستباف (QIT) & .3 \\
\hline$\cdot M$ & رود درآمدى بهدليل رشد ثامناسب قيمت فرش دستباف در مقايسه با ديكر كالاهاى توليدى (QP) & $y^{8}$ \\
\hline V/F & ضعف نظام برنامهريزى توسعه روستايى در روثقبخشى به توليد صنعت فرش دستباف (QIf) & 4 \\
\hline $1 / 10$ & ضعف سياستهاى حمايتى دولت از فرشبافان (بيمه و...) و ناكارآملى نههادهاى مسئول (Q10) & \\
\hline$y \cdot 9$ & سختى كار قالى بافى و آسيب:هاى جسمى ناشى از آن (QII) & \\
\hline$V \cdot 1$ & عقبماندكى فنى در توليد فرش دستباف (Qr) & $y^{3}$ \\
\hline.$/ 99$ & دستيابى روستاييان به منابع معيشتى جديد در ديكر بخش هاى اقتصادى (Q1) & \\
\hline V/9 & تمايلنداشتن جوانان، بهويره دختران جوان روستايى، به فعاليت فرشبافى و يادكيرى مهارتهاى آن (QV) & y \\
\hline $1 / 8 \pi$ & دستيابى روستاييان به منايع معيشتى جديل در ديكر بخش هاي اقتصادى (QI) & \\
\hline $1 / 4$ & بهرهورى كمتر فرشبافى در مقايسه با ديكر فعاليتهاي اقتصادى (QD) & 釷 \\
\hline$\cdot / M$ & عقباماندكى فنى در توليد فرش دستباف (QY) & $3^{3} \cdot 3^{3}$ \\
\hline
\end{tabular}

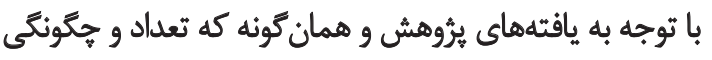

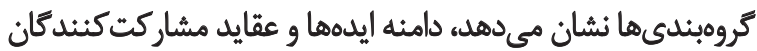

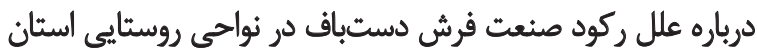

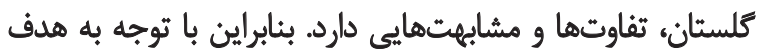

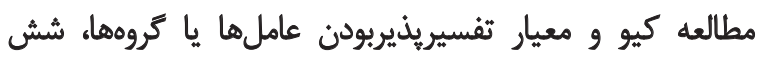

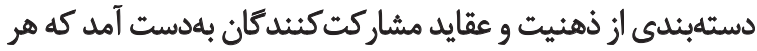

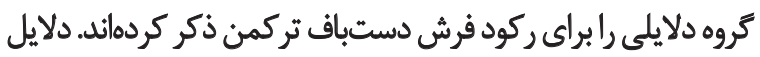
اين كروهها از اين قرار است:

ا. كروه اول: اعضاى كروه معتقدند ضعف خلاقيت و نوآورى در

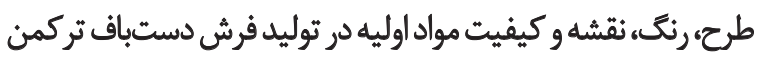
كاهش كيفيت اين محصول را بهدنبال داشته است. درعين حال آنها
جوامع روستايى، بلويره در ابعاد اقتصادى ميسّر، نشده است.

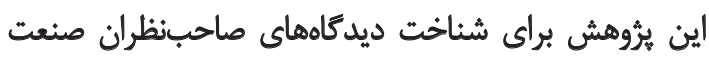

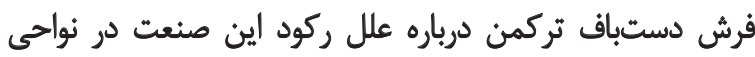

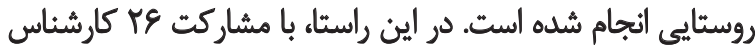

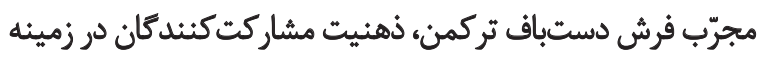

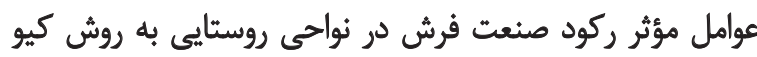

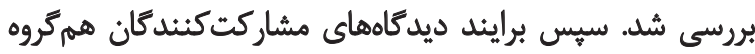

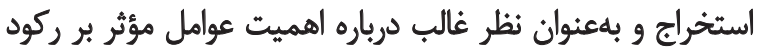

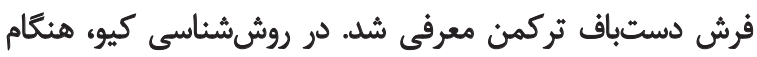

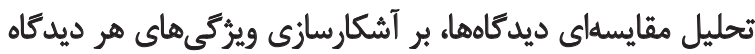

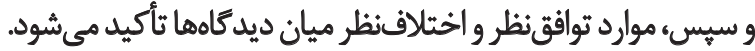




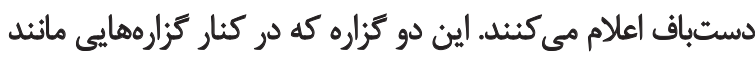

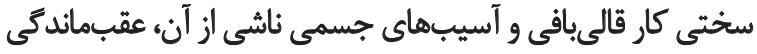

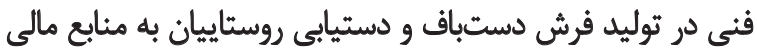

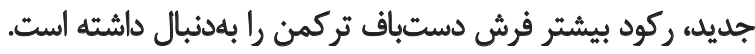

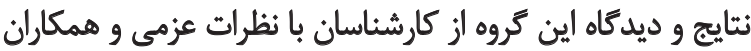

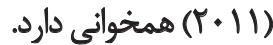

و. تروه ششم: تمايلنداشتن جوانان، بلويره دختران جوان

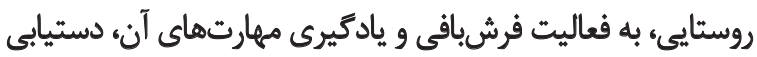

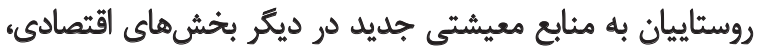

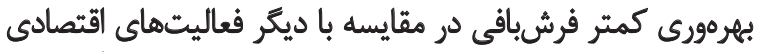

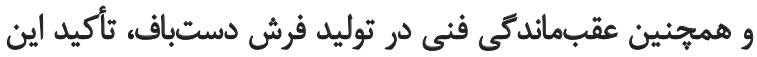

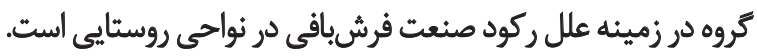

با توجه به تحليل دادهها در نرمافزار SPSS ونتايج حاصل از آن

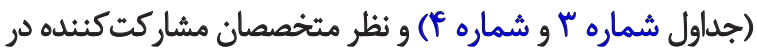

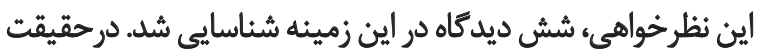

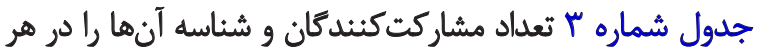

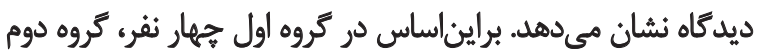

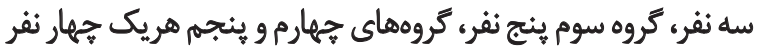
و كروه ششم شش نفر حضور داشتئد.

در جدول شماره ه، امتيازهاى هر كزاره در كروهاي

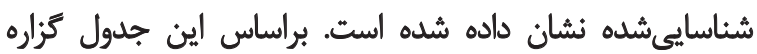

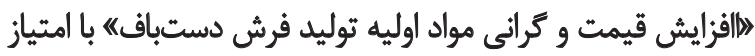

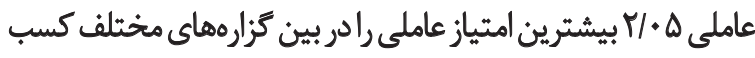

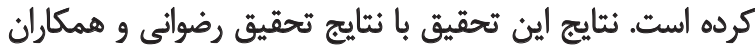

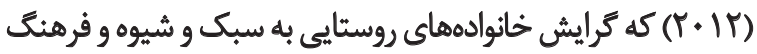

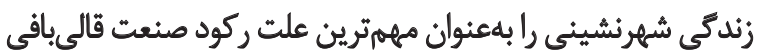

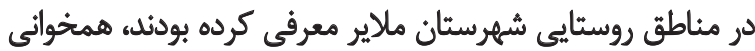

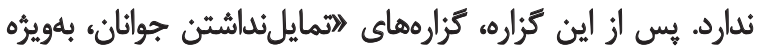

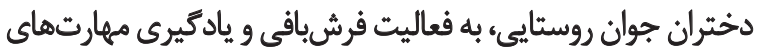

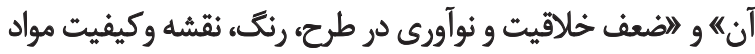

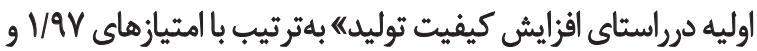

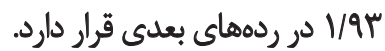

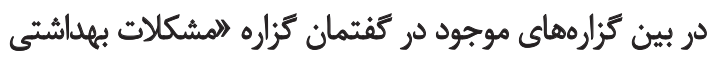

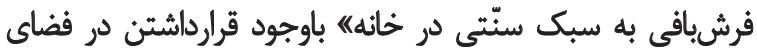

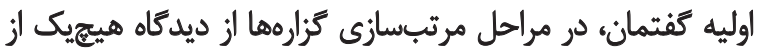

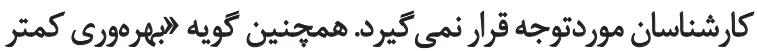

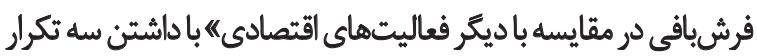

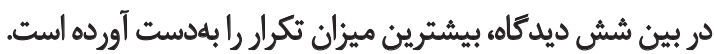

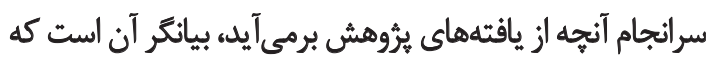

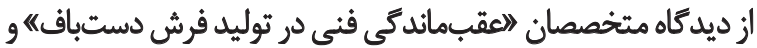

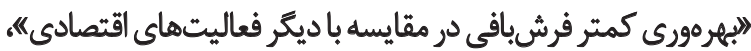

مشكلات بازاريابى فرش دستباف را نيز در ركود اين صنعت مؤثر

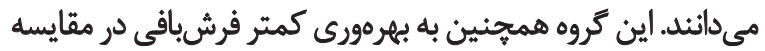

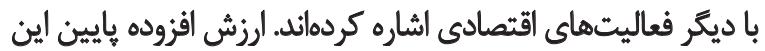

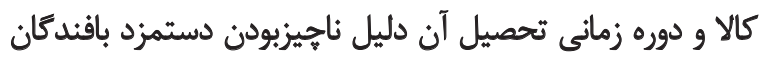

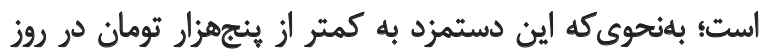

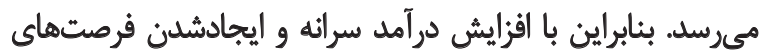

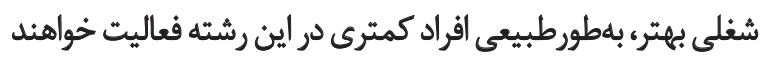

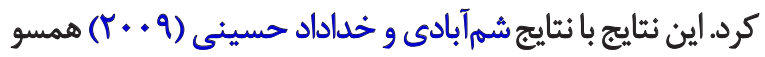

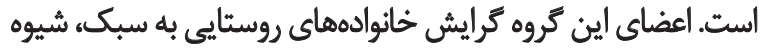

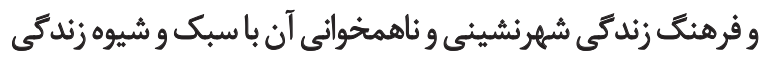

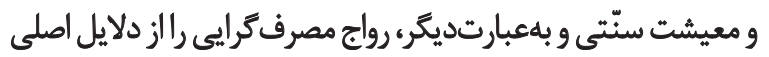

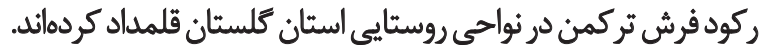

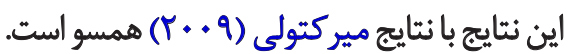

r. گروه دوم: اعضاى اين گروه بر اين باورند كه عقبماندقى

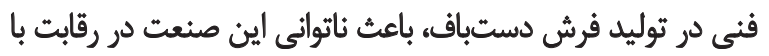

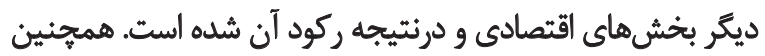

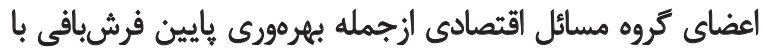

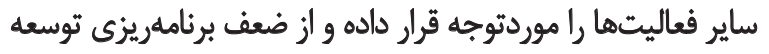

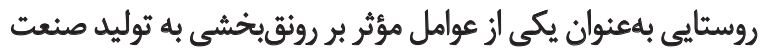
فرش دستباف و ركود آن ياد كردهاند.

ب. كروه سوم: مشاركت كنثدكان اين كروه بهشدت معثقدند كه

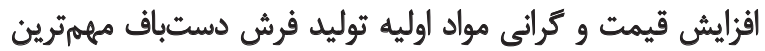

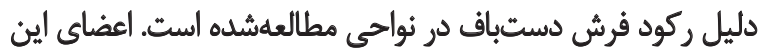

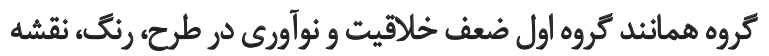

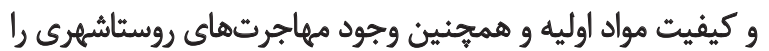
در ركود صنعت فرش دستباف تركمن مؤثر مى دانيند.

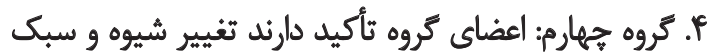

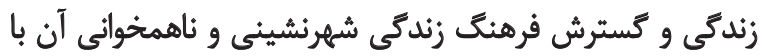

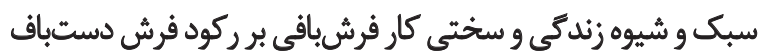

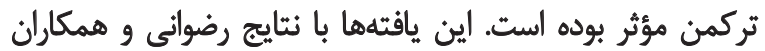

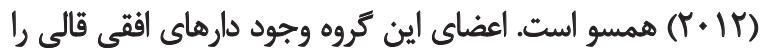

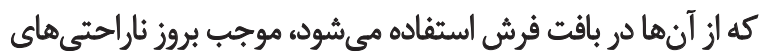

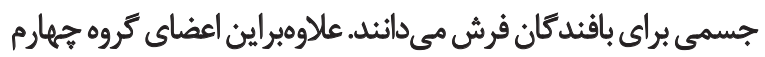

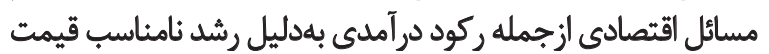

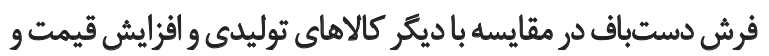

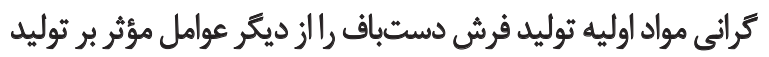
فرش تركمن برشمردهاند.

ه. كروه ينجم: اعضاى اين كروه كزارههايى از قبيل ضعف نظام

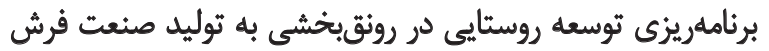

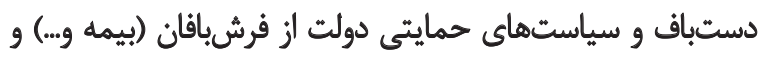

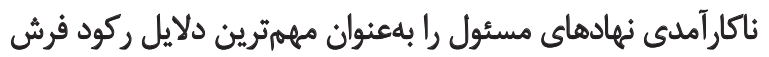




\section{References}

Adeli, Z. (2013). [Carpet clusters in Golestan Province (Persian)]. Retrieved from http://golestancarpets.com/index.php/intro/introduction.

Azouii, A. (2003). [Investigation of global markets of hand-woven carpets and identification their global market restriction and tariffs (Persian)]. Paper presented at the $1^{\text {th }}$ National Conference on Carpet Research, Tehran, Iran, 19-20 October 2003.

Darabi, H. (2005). [Spatial impacts of development activities using people participation: a case study on Kashan village's settlement (Persian)] ( $\mathrm{PhD}$ thesis). Tehran: Tarbiat Modares University.

Duenckmann, F. (2010). The village in the mind: applying Q-methodology to re-constructing constructions of rurality. Journal of Rural Studies, 26(3), 284-95.

Ellingsen, I. T., Størksen, I., \& Stephens, P. (2010). Q methodology in social work research. International Journal of Social Research Methodology, 13(5), 395-409.

Esfandiari, A., Tajpoury, Q., \& Pakzad, A. R. (2010). [Factors affecting the export of turkmen carpet (Persian)]. Goljaam, 17, 71-84

Exel, J. V., Graaf, G., \& Brouwer, W. (2007). Care for a break? An investigation of informal caregivers' attitudes toward respite care using Q-methodology. Health Policy, 83(2), 332-42.

Eynali. J., \& Taher Khani, M. (2006). [Evaluation of rural social welfare complexes in rural welfare (Case study: Sojas, Kaase and Garmab villages of Khodabandeh city) (Persian)]. Quarterly Modarres Human Sciences, 9(4), 101-16.

Heydari Shakib, R. (2011). [The Investigation and identification of traditional dyeing in Kashan city (Persian)]. Journal of Ketabe Mahe Honar, 142, 96-102.

Jafar Najad, A., Sajiadi Panah, A., Saffavi Mirmahaleh, S. R., \& Ajali Ghashlajoghi, M. (2009). [Electronic commerce/electronic business/hindrances/master plans/Iranian hand-woven carpet (Persian)]. Iranian Journal of Trade Studies, 13(52), 1-34.

Khoshgooyanfard, A. R. (2007). [Q-methodology (Persian)]. Tehran: IRIB Research Center.

Mir Kattouli, J. (2009). [A study of economic-social reasons for the quality decline of Turkman carpets (Persian)]. Geographical Research, 24(3), 51-66.

Poursadegh, N., Bohlooli. N., \& Hajikhani. M. (2010). [The Role of Carpet Hand-Weaving Cooperatives of Janjan Province on Increasing the Exports of Hand-Woven (Persian)]. Ta'avon, 21(3), 155-70.

Saberi, E. (2003). [The role of hand-woven carpets industry on producing job opportunities in urban and rural areas. National Research Seminar on hand-woven carpets (Persian)]. Paper presented at the $1^{\text {th }} \mathrm{Na}$ tional Conference on Carpet Research, Tehran, Iran, 19-20 October 2003.

Shajari, H., \& Ghavami, M. (2003). [Iranian Carpet Export to European Union and the Effect of Foreign Competition on them (Persian)]. Paper presented at the $1^{\text {th }}$ National Conference on Carpet Research, Tehran, Iran, 19-20 October 2003.

Sham Abadi, M. A., \& Khodadad Hossini, S. H. (2009). [Export marketing of Persian carpet (Persian)]. Iranian Journal of Trade Studies, 11(43), 1-34.

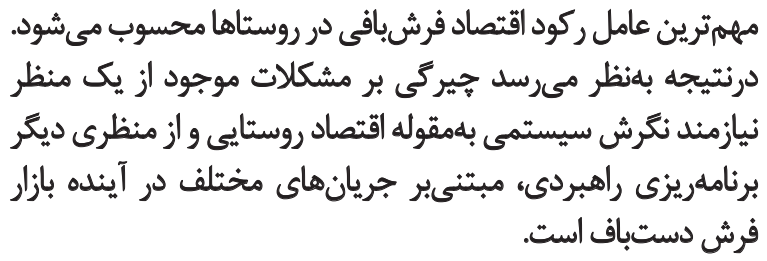


Watts, S., \& Stenner, P. (2012). Doing Q Methodological Research: Theo$r y$, Method \& Interpretation. London: Sage Publication.

Wright, P. N. (2013). Is Q for you? Using Q methodology within geographical and pedagogical research. Journal of Geography in Higher Education, 37(2), 152-63.

Statistical Center of Iran. (2011). National population and housing census. Retrieved from www.amar.org.ir.

Zare Chahouki, M. R. (2011). [Data Analysis in Natural Resources Research Using SPSS Software (Persian)]. Tehran: Tehran University Press.

Ziaei, A. (2002). [Analysis of Productivity of production factors affecting hand-woven carpets on the process of socioeconomic development of rural communities, a case study Harris hand-woven carpets-Azerbaijan (Persian)] (MSc. thesis). Tehran: Tarbiat Modares University. 